\title{
HETEROLOGOUS PHYTASE EXPRESSION IN THE FOOD FILAMENTOUS FUNGUS Aspergillus oryzae USING THE ADDED RICE HUSK CULTIVATION MODEL
}

\author{
Thai Hanh Dung ${ }^{1,2}$, Tran Van Tuan ${ }^{1,2, *}$ \\ ${ }^{1}$ Department of Microbiology, Faculty of Biology, University of Science, \\ Vietnam National University, Hanoi \\ ${ }^{2}$ Genomics Unit, Key Laboratory of Enzyme and Protein Technology, \\ University of Science, Vietnam National University, Hanoi
}

Received 10 March 2020, accepted 10 June 2020

\begin{abstract}
Aspergillus oryzae, a safe filamentous fungus, is widely used in food and enzyme production. In this study, we examined a cultivation model using rice husks as carrier to assess the capacity of recombinant protein production in $A$. oryzae. The model was first tested with the $A$. oryzae strain expressing the DsRed reporter gene. The expression of DsRed was easily detected by the pink color of the fungal mycelium on culture media and under a fluorescence microscope. The model was then evaluated with the phyA gene encoding a phytase from the fungus Aspergillus fumigatus. The phyA expression cassette regulated by the amyB promoter was permanently integrated into the genome of $A$. oryzae via Agrobacterium tumefaciens-mediated transformation with the pyrG nutritional marker. The results showed that transgenic A. oryzae strains carrying 2-3 copies of the phyA gene in their genomes exhibited a significant increase in phytase activity on agar medium supplemented with phytate. With rice husks added, these transgenic strains could secrete the recombinant phytase into the culture and phytase activity of the crude enzyme solution increased by 4.3 times compared to the original A. oryzae. The established cultivation model and the transgenic strategy in this study represent a potential approach for being exploited in the production of secreted recombinant enzymes for animal feeds.
\end{abstract}

Keywords: Aspergillus oryzae, Agrobacterium tumefaciens-mediated transformation, DsRed, recombinant phytase, rice husk.

Citation: Thai Hanh Dung, Tran Van Tuan, 2020. Heterologous phytase expression in the food filamentous fungus Aspergillus oryzae using the added rice husk cultivation model. Academia Journal of Biology, 42(2): 75-84. https://doi.org/10.15625/2615-9023/v42n2.14985.

*Corresponding author email: tuantran@vnu.edu.vn

(C2020 Vietnam Academy of Science and Technology (VAST) 


\section{INTRODUCTION}

Aspergillus oryzae, a safe filamentous fungus, has been widely used in Asian countries for the production of traditional foods and beverages such as soy sauce, miso and sake (Barbesgaard et al., 1992; Machida et al., 2008). A. oryzae has the ability to express and secret a large amount of recombinant enzymes into the culture media as reported for aspartic protease and lipase from Rhizomисor miehei (Christensen et al., 1988; Huge-Jensen et al., 1989). Currently, the industrial production of some recombinant enzymes using A. oryzae as the host has been approved. Rhizomucor miehei lipase expressed in A. oryzae has been used for humans in Denmark (Barbesgaard et al., 1992).

Phytase is one of the most prominent enzymes for animal feed, accounting for about $60 \%$ of the enzyme market for cattle and poultry nutrition, which costs approximately $\$ 350$ million per year. Phytase is present as an additive in about $70 \%$ of commercial animal feeds. Phytase (also known as myo-inositol hexakisphosphate phosphohydrolase) hydrolyzes phytic acid (or phytate), releasing inorganic phosphorus that is essential for animal metabolism. Monogastric animals, which do not possess phytases, are unable to metabolize phytate from grains - the main ingredients of industrial animal feeds. Unmetabolized phytate may be released by the animals into the environment as waste, causing pollution (Haefner et al., 2005; Rao et al., 2009). Although phytases have been isolated from various microbial sources, only phytases from certain microorganisms with attractive characteristics including the high rate of phytate hydrolysis, acidic $\mathrm{pH}$ tolerance and heat stability during feed pelleting process are widely used in the industrial production (Rao et al., 2009). Phytase from the filamentous fungus Aspergillus fumigatus has the ability to recover its activity level after heat treatment whereas many other phytases are usually inactivated during feed pelleting process (Pasamontes et al., 1997). However, the direct use of A. fumigatus for enzyme production is not allowed because this fungus is an opportunistic human pathogen (Varga et al., 2011). As a result, different strategies based on genetic engineering have been used to generate recombinant fungal strains with safety assurance for industrialscale enzyme production (Punt et al., 2002).

Recently, our research group has succeeded in establishing a highly efficient genetic transformation system for the food filamentous fungus $A$. oryzae using the bacterium Agrobacterium tumefaciens as a DNA transfer tool (Nguyen et al., 2016; Nguyen et al., 2017). The A. tumefaciensmediated transformation (ATMT) method has many advantages, especially the direct use of fungal spores as the transformation material and the target gene located in TDNA is stably integrated into the fungal genome (Michielse et al., 2005). In this study, we transferred the phyA gene encoding a phytase from the opportunistic human pathogen $A$. fumigatus into the genome of the food fungus $A$. oryzae using the ATMT method. Instead of common antibiotic resistance genes, the $p y r G$ gene was used as a nutritional marker for selecting fungal transformants. Therefore, the transgenic $A$. oryzae strains expressing the phytase gene would be safe for recombinant production.

\section{MATERIALS AND METHODS}

\section{Microbial strains, plasmids and PCR primers}

The strains and plasmids used in this study are listed in Table 1.

Primers for PCR amplifications listed in table 2 were synthesized by Integrated DNA Technologies (IDT) Inc. (Singapore). The primer pair (PhyA-F/PhyA-R) employed for the amplification of the phyA gene was designed with Primer3 based on the $A$. fumigatus phyA sequence (accession number: Afu4g08630). The primer pair (pyrG-RT-F/pyrG-RT-R) for the amplification of the $\operatorname{pyr} G$ marker was based on the pyrG gene sequence (accession number: AO090011000868). These two 
sequences were extracted from the http://www.aspergillusgenome.org. Aspergillus genome database at the link:

Table 1. Microbial strains and plasmids used in this study

\begin{tabular}{|c|c|c|}
\hline Strain/ plasmid & Description & Reference \\
\hline $\begin{array}{l}\text { Escherichia coli } \\
\text { DH5 } \alpha\end{array}$ & $\begin{array}{l}\mathrm{F}^{-} \text {endA1 hsdR17 supE44 thi-1 } \lambda^{-} \text {recAl gyrA96 relA1 } \\
\text { deoR } \Delta(\text { lacZYA-argF)-U169 } \Phi 80 \mathrm{~d} \text { lacZDM15 }\end{array}$ & Nguyen et al., 2016 \\
\hline $\begin{array}{l}\text { A. tumefaciens } \\
\text { AGL1 }\end{array}$ & C58, recA::bla, pTiBo542 $4 \mathrm{~T}-\mathrm{DNA}, \mathrm{Mop}^{+}, \mathrm{Cb}^{\mathrm{R}}$ & Nguyen et al., 2016 \\
\hline $\begin{array}{l}\text { A. fumigatus } \\
\text { VTCC } 31414\end{array}$ & The wild-type A. fumigatus isolated in Vietnam & $\begin{array}{l}\text { IMBT, Vietnam National } \\
\text { University, Hanoi }\end{array}$ \\
\hline A. oryzae RIB40 & The wild-type A. oryzae originated from Japan & Machida et al., 2008 \\
\hline $\begin{array}{l}\text { A. oryzae } \\
\text { AUT1-PID }\end{array}$ & $\begin{array}{l}\text { niaD- }{ }^{-} C^{-} \text {ade } A^{-} \Delta \arg B:: a d e A^{-} \Delta t p p A:: \arg B \\
\Delta p e p E:: a d e A \text { aut } 1^{-} \Delta \operatorname{lig} D \Delta p y r G\end{array}$ & Zhu et al., 2013 \\
\hline $\begin{array}{l}\text { A. oryzae } \\
\text { AUT1-R1 }\end{array}$ & $\begin{array}{l}\text { The AUT1-PID strain expressing the DsRed } \\
\text { fluorescent reporter gene }\end{array}$ & Nguyen et al., 2017 \\
\hline $\mathrm{pEX} 2 \mathrm{~B}$ & $\begin{array}{l}\text { The binary vector with the pyrG marker and the } \\
\text { DsRed reporter gene under the regulation of the } A \text {. } \\
\text { oryzae amyB promoter }\end{array}$ & Nguyen et al., 2017 \\
\hline pEX2B-phyA & $\begin{array}{l}\text { The binary vector with the pyrG marker and the } A \text {. } \\
\text { fumigatus phy } A \text { gene under the regulation of the } A \text {. } \\
\text { oryzae amy } B \text { promoter }\end{array}$ & This study \\
\hline
\end{tabular}

Table 2. Primers used in this study

\begin{tabular}{|l|l|c|l|}
\hline Primer name & \multicolumn{1}{|c|}{$\begin{array}{c}\text { Primer sequence }\left(5^{\prime}-3^{\prime}\right) \text { with the } \\
\text { underlined sites for restriction enzymes }\end{array}$} & $\begin{array}{c}\text { Product } \\
\text { size }\end{array}$ & \multirow{2}{*}{ Reference } \\
\hline ITS1 & TCCGTAGGTGAACCTGCGG & \multirow{2}{*}{$597 \mathrm{bp}$} & \multirow{2}{*}{ White et al., 1990} \\
\hline ITS4 & TCCTCCGCTTATTGATATGC & \multirow{2}{*}{$1.51 \mathrm{~kb}$} & This study \\
\cline { 1 - 2 } PhyA-F & $\begin{array}{l}\text { GGGCACGTGATGAAAAAGCTATAT } \\
\text { AATGGCCGG }(P m l I)\end{array}$ & \multirow{2}{*}{$196 \mathrm{bp}$} & This study \\
\hline pyrG-RT-F & $\begin{array}{l}\text { GGGGATCCTCAACTAAAGCACTCTC } \\
\text { CCCA }(\text { BamHI })\end{array}$ & CGGAAACACAGTCCAAAAGC & \\
\cline { 1 - 2 } pyrG-RT-R & CAAAGATCCCTTGGAGGTCA & &
\end{tabular}

\section{Cultivation media}

Potato dextrose agar (PDA) medium was used for cultivating the wild-type strains $A$. oryzae RIB40 and A. fumigatus VTCC 31414.

DPY medium (2\% glucose, $1 \%$ peptone, $0.5 \%$ yeast extract, $0.5 \% \quad \mathrm{KH}_{2} \mathrm{PO}_{4}, 0.05 \%$ $\mathrm{MgSO}_{4} .7 \mathrm{H}_{2} \mathrm{O}, \quad \mathrm{pH}$ 5.5) with required supplements $(0.1 \%$ uracil, $0.1 \%$ uridine $)$ was used for collecting spores of the AUT1-PID strain. The AUT1-PID strain, which was genetically engineered from A. oryzae RIB40, is a hyper-producing strain for recombinant protein production (Zhu et al., 2013).
$\mathrm{M}+$ met medium $\quad\left(0.2 \% \quad \mathrm{NH}_{4} \mathrm{Cl}, \quad 0.1 \%\right.$ $\left(\mathrm{NH}_{4}\right)_{2} \mathrm{SO}_{4}, 0.05 \% \mathrm{KCl}, 0.05 \% \mathrm{NaCl}, 0.1 \%$ $\mathrm{KH}_{2} \mathrm{PO}_{4}, 0.05 \% \quad \mathrm{MgSO}_{4}, 0.002 \% \mathrm{FeSO}_{4}, 2 \%$ glucose, $0.15 \%$ methionine, $\mathrm{pH} 5.5$ ) was used as a minimal medium for selection of fungal transformants (Zhu et al., 2013).

The induction medium (IM) was supplemented with $0.05 \%$ uridine, $0.05 \%$ uracil and $200 \mu \mathrm{M}$ acetosyringone (AS). The liquid IM contained salts of minimal medium (MM salts), $40 \quad \mathrm{mM} \quad 2$-( $N$-morpholino) ethanesulfonic acid (MES), $10 \mathrm{mM}$ glucose, $0.5 \%(\mathrm{w} / \mathrm{v})$ glycerol. The solid IM contained 
only $5 \mathrm{mM}$ glucose. The solution of MM salts (g/l) consisted of $2.05 \mathrm{~g} \mathrm{~K}_{2} \mathrm{HPO}_{4}, 1.45 \mathrm{~g}$ $\mathrm{KH}_{2} \mathrm{PO}_{4}, 0.15 \mathrm{~g} \mathrm{NaCl}, 0.5 \mathrm{~g} \mathrm{MgSO}_{4} .7 \mathrm{H}_{2} \mathrm{O}$, $0.1 \mathrm{~g} \mathrm{CaCl}_{2} .6 \mathrm{H}_{2} \mathrm{O}, 0.5 \mathrm{~g}\left(\mathrm{NH}_{4}\right)_{2} \mathrm{SO}_{4}, 0.0025 \mathrm{~g}$ $\mathrm{FeSO}_{4} .7 \mathrm{H}_{2} \mathrm{O}$ (Nguyen et al., 2016).

Phytase screening medium (PSM) contained $1 \%$ glucose, $0.4 \%$ sodium phytate, $0.2 \% \quad \mathrm{CaCl}_{2} .6 \mathrm{H}_{2} \mathrm{O}, \quad 0.5 \% \quad \mathrm{NH}_{4} \mathrm{NO}_{3}, \quad 0.05 \%$ $\mathrm{KCl}, \quad 0.05 \% \quad \mathrm{MgSO}_{4} .7 \mathrm{H}_{2} \mathrm{O}, \quad 0.001 \%$ $\mathrm{FeSO}_{4} .7 \mathrm{H}_{2} \mathrm{O}, 0.001 \% \mathrm{MnSO}_{4} \cdot \mathrm{H}_{2} \mathrm{O}$.

For a solid medium, 2\% agar was added. All media were autoclaved before use.

\section{Spore preparation}

Fungal strains were cultivated on agar plates for 3-5 days at $30^{\circ} \mathrm{C}$. Sterile distilled water was added and a sterile glass spreader was used to scrap the agar surface. The liquid was collected and filtered through Miracloth (Calbiochem, Germany). The filtrate was then centrifuged at $5000 \mathrm{rpm}$ for $10 \mathrm{~min}$. Collected spore pellets were washed twice with sterile distilled water and resuspended in sterile distilled water to obtain the final spore suspension. Fungal spore concentration was measured using a Thoma counting chamber and adjusted to $10^{6}$ or $10^{7}$ spores $/ \mathrm{ml}$ for further experiments.

\section{Total DNA extraction}

The extraction of total DNA from fungal mycelium was based on the procedure from our previous study (Nguyen et al., 2016) or using the commercial E.Z.N.A. ${ }^{\circledR}$ Fungal DNA Mini Kit (Omega Bio-tek, USA).

\section{Total RNA extraction and cDNA synthesis}

Total RNA was extracted from fungal mycelium using ANAPURE ${ }^{\circledR}$ RNA Mini Kit (ANABIO R\&D JSC, Vietnam). RNA samples were digested with DNase I (Qiagen, Germany) at $37^{\circ} \mathrm{C}$ for $30 \mathrm{~min}$ to remove total DNA. The enzyme DNase I was then inactivated at $75^{\circ} \mathrm{C}$ for $15 \mathrm{~min}$. The RNA samples were immediately kept in ice. The purity of the RNA samples was then examined with PCR using the primer pair ITS1/ITS4 (Table 2) specific for the ITS region of ribosomal DNA. The purified RNA was converted into cDNA using ProtoScript ${ }^{\circledR}$ First Strand cDNA Synthesis (New England Biolabs, USA).

Construction of the binary vector for expressing the phyA gene from A. fumigatus

The full-length coding sequence of the phyA gene was amplified from the $A$. fumigatus cDNA sample with PCR using the specific primer pair PhyA-F/PhyA-R (Table 2 ). Phusion ${ }^{\circledR}$ high-fidelity DNA polymerase (Thermo Scientific, USA) was used to ensure the accuracy of PCR amplification. The obtained PCR product was purified with Wizard $^{\circledR}$ SV Gel and PCR Clean-Up System (Promega, USA). The purified PCR product was digested with PmlI and BamHI and ligated into the binary vector $\mathrm{pEX} 2 \mathrm{~B}$, which was also digested with the same restriction enzymes. The resultant plasmid was transformed into the competent $E$. coli $\mathrm{DH} 5 \alpha$ cells for propagation. The recombinant plasmid was purified with Wizard ${ }^{\circledR}$ Plus SV Minipreps DNA Purification System (Promega, USA). The existence of the phyA expression cassette was confirmed by PCR using the specific primer pair PhyA-F/PhyA$\mathrm{R}$ and by digestion with suitable restriction enzymes as well as by DNA sequencing. The constructed binary vector was named pEX2B-phyA.

Transfer of the phyA expression cassette into the $A$. oryzae AUT1-PID strain using $A$. tumefaciens

The binary vector pEX2B-phyA was transferred into the A. tumefaciens AGL1 cells by the electroporation method. A single A. tumefaciens colony harboring the vector was inoculated in a conical flask containing $20 \mathrm{ml}$ of the liquid Luria-Bertani (1\% peptone, $0.5 \%$ yeast extract powder, $0.5 \%$ $\mathrm{NaCl})$ supplemented with kanamycin $(100$ $\mathrm{mg} / \mathrm{l}$ ) through shaking at $200 \mathrm{rpm}$ and $28^{\circ} \mathrm{C}$ for 15-17 h. One milliliter of the culture was mixed with $9 \mathrm{ml}$ of induction medium (IM) and $200 \mu \mathrm{M}$ acetosyringone (AS). The bacteria were additionally incubated for $6 \mathrm{~h}$ at $28^{\circ} \mathrm{C}, 200 \mathrm{rpm}$ until the $\mathrm{OD}_{600 \mathrm{~nm}}$ reached 0.60.8. A mixture of $100 \mu \mathrm{l}$ of the AUT1-PID 
spore suspension $\left(10^{7}\right.$ spores $\left./ \mathrm{ml}\right)$ and $100 \mu \mathrm{l}$ of the induced AGL1 suspension was spread on 90-mm cellulose filter paper (Sartorius, Germany), which was placed on the IM agar plate consisting of $200 \mu \mathrm{M}$ AS, $0.05 \%$ uridine $(\mathrm{w} / \mathrm{v})$ and $0.05 \%$ uracil $(\mathrm{w} / \mathrm{v})$. The plate was kept in darkness for $60 \mathrm{~h}$ at $22^{\circ} \mathrm{C}$. After that, the filter paper was transferred to a new plate containing $\mathrm{M}+$ met medium supplemented with cefotaxime $(300 \mathrm{mg} / \mathrm{l})$ for fungal selection. This plate was incubated at $30^{\circ} \mathrm{C}$ for $5-7$ days until fungal transformants appearing on the filter paper membrane.

\section{Examination of the transformants}

The existence of the phyA gene from $A$. fumigatus in the genome of the obtained $A$. oryzae transformants was confirmed by PCR using the specific primer pair PhyA-F/PhyA$\mathrm{R}$ (Table 2). For examining the recombinant phytase expression, fungal transformants were directly grown on PSM supplemented with $0.15 \%$ methionine. After 3-5 days, a zone of clearance surrounding the transformants was observed.

\section{Determination of the phyA copy number in the transformants with real-time PCR}

Total DNA was isolated from the selected A. oryzae transformants using E.Z.N.A. ${ }^{\circledR}$ Fungal DNA Mini Kit (Omega Bio-tek, USA). DNA quantifications by realtime PCR were carried out with IQ5 realtime PCR system (Bio-Rad, USA). HotStartIT SYBR Green qPCR Master Mix (Affymetrix, USA) and the primer pair pyrGRT-F/pyrG-RT-R for the pyrG gene (Table 2 ) were included. The $2^{-\Delta \mathrm{Ct}}$ formula was used for determining the phyA gene copy number, in which $\Delta \mathrm{Ct}$ corresponds to $\mathrm{Ct}$ (in the strain of interest)-Ct (in the reference strain) (Schmittgen \& Livak, 2008).

\section{Extraction of crude enzyme solution}

One milliliter of a spore suspension $\left(10^{7}\right.$ spores $/ \mathrm{ml}$ ) harvested from the transformants was added to a $250 \mathrm{ml}$ autoclaved flask containing $10 \mathrm{ml}$ of liquid $\mathrm{M}+\mathrm{met}$ and $4 \mathrm{~g}$ of dried clean rice husks. Rice husks were used as the carrier in order to provide ventilation for fungal growth. After incubation at $30^{\circ} \mathrm{C}$ for different amounts of time, $30 \mathrm{ml}$ of sodium acetate $(200 \mathrm{mM}, \mathrm{pH} 6)$ was added. The mixture was shaken at $200 \mathrm{rpm}$ for 20 min. The crude enzyme supernatant was collected by filtration using Miracloth (Calbiochem, Germany) and centrifugation at $5000 \mathrm{rpm}, 4^{\circ} \mathrm{C}$ for $15 \mathrm{~min}$. The crude enzyme solution was kept at $4^{\circ} \mathrm{C}$ for later use or used directly for phytase activity assays.

\section{Phytase activity assay}

Phytase activity was determined according to Heinonen \& Lahti (1981) (Heinonnen \& Lahti, 1981) with some modifications. The reaction included $125 \mu \mathrm{l}$ of the crude enzyme solution, $125 \mu \mathrm{l}$ sodium phytate $(15 \mathrm{mM})$ and $125 \mu \mathrm{l}$ sodium acetate buffer $(200 \mathrm{mM}, \mathrm{pH}$ 5.5). The reaction mixture was incubated at $55^{\circ} \mathrm{C}$ for $30 \mathrm{~min}$, and terminated by adding 0.5 $\mathrm{ml}$ of $15 \%$ TCA. The color formation was achieved by transferring $125 \mu \mathrm{l}$ of the mixture into $1 \mathrm{ml}$ of AAM solution $(10 \mathrm{mM}$ ammonium molybdate, $100 \%$ acetone, $5 \mathrm{~N}$ sulfuric acid, 1:2:1). After $2 \mathrm{~min}, 100 \mu \mathrm{l}$ of $1 \mathrm{M}$ citric acid was added and the absorbance at 355 $\mathrm{nm}$ was determined after termination. The nontransgenic strain AUT1-PID was selected as the control and each experiment was repeated independently three times. One unit (U) of phytase activity is defined as the amount of enzyme required for catalysis to produce one micromole of inorganic phosphate per minute under standard assay conditions. A standard curve was constructed using $\mathrm{KH}_{2} \mathrm{PO}_{4}$ at different concentrations.

\section{RESULTS AND DISCUSSION}

\section{A. oryzae AUT1-PID represents an excellent host for heterologous expression}

A. oryzae AUT1-PID used in this study is a hyper-producing strain for recombinant protein production. This strain was genetically engineered from the wild strain A. oryzae RIB40 (Zhu et al., 2013). The DsRed expressing transformant (AUT1-R1) formed the pink mycelium, which could be observed even with the naked eye (Nguyen et al., 2017). This strain was selected for evaluating the suitability of the rice husk 
cultivation model. The expression of the DsRed reporter was regulated by the strong $a m y B$ promoter (Figure 1A). This promoter could be induced by starch or maltose, and repressed by glucose (Tsuchiya et al., 1992). In this study, we reported that glucose was still able to activate the function of the $a m y B$ promoter, but it was not as strong as the specific inducer maltose (Figure 1B). The $a m y B$ promoter worked better for regulating gene expression in the solid-state cultivation rather than in the liquid-state fermentation. However, the collection of secreted enzymes from agar media seemed to be complicated. Here, we constructed a cultivation model using rice husks as the carrier for fungal growth. This is a promising approach for low-cost isolation of secreted enzymes. We tested the growth of the transgenic strain AUT1-R1 on the rice husk cultivation model and the results showed a strong expression of the DsRed gene, which resulted in the pink mycelium on agar plates. When observed under Axioplan fluorescence microscope, the red mycelium fully covered and adhered to the rice husks (Figure 1C).

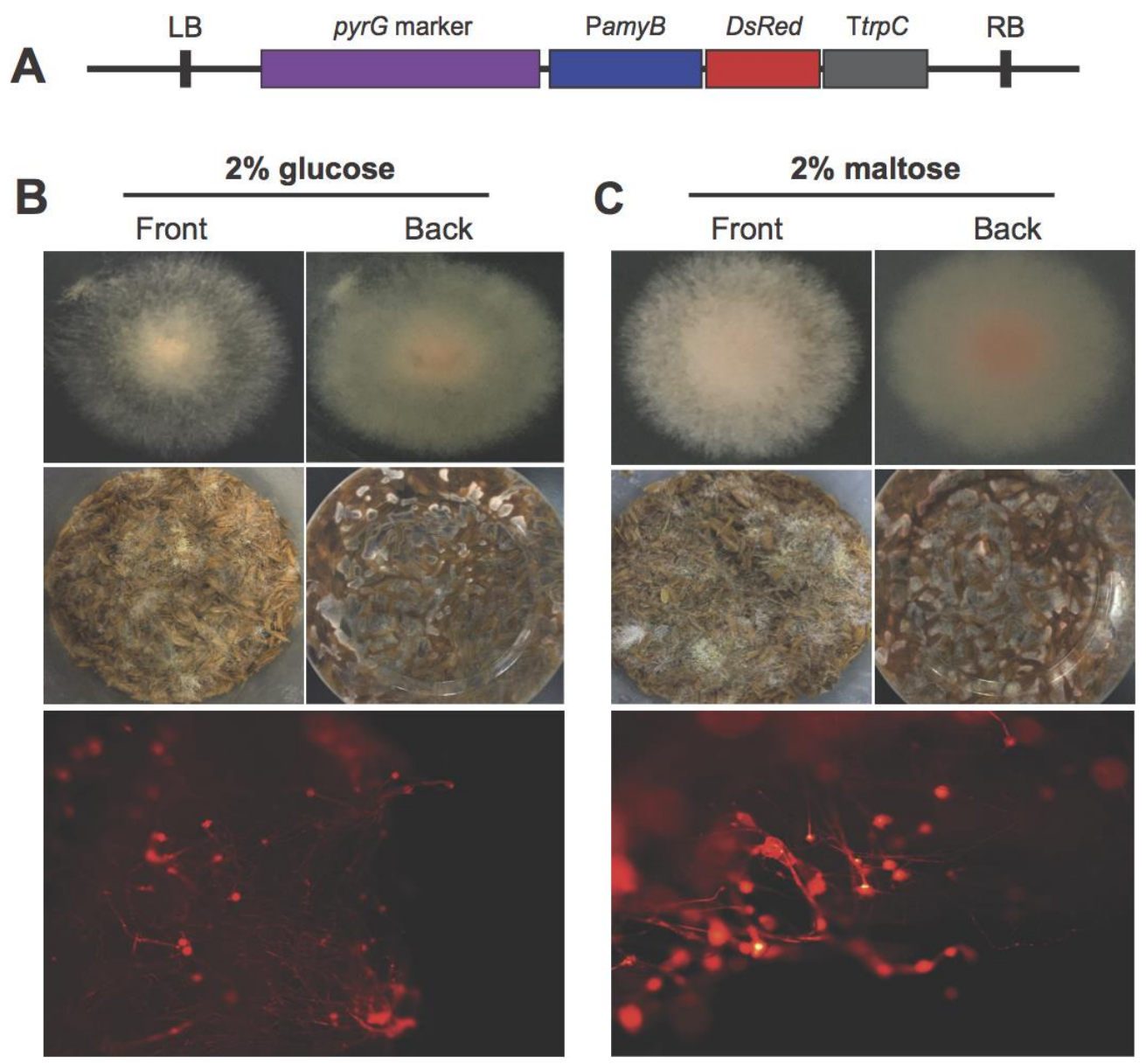

Figure 1. Heterologous expression of the DsRed reporter gene in A. oryzae. Glucose and maltose were used as the sole carbon sources to examine the ability for gene expression regulation of the $a m y B$ promoter. (A) The structure of T-DNA of the binary vector pEX2B. (B) The expression of the DsRed gene in AUT1-R1 cultivated on the agar medium and on the added rice husk medium with glucose as the sole carbon source. The mycelium of AUT1-R1 from the rice husk cultivation model was observed under the fluorescence microscope. (C) A similar experiment was carried out with maltose as the sole carbon source 
The successful construction of a binary vector carrying the $p h y A$ expression cassette for the transformation of A. oryzae AUT1-PID

The coding sequence of the phyA gene from the opportunistic human pathogen A. fumigatus was amplified from a cDNA sample and inserted into the pEX2B binary vector for genetic transformation of the safe filamentous fungus A. oryzae. The DsRed reporter gene in pEX2B was replaced with the phyA gene. The expression of phyA was controlled by the $a m y B$ promoter (Figure 2). Transfer of the phyA expression cassette from the binary vector pEX2B-phyA into A. oryzae AUT1-PID was conducted as previously described (Nguyen et al., 2016). In this strategy, the $p y r G$ gene was recruited as a selection marker and the wellknown Agrobacterium tumefaciens AGL1 strain was used as a tool for gene transfer into the fungal genome. The utilization of the $A$. oryzae pyrG gene as the nutritional marker for genetic transformation in $A$. oryzae would help to construct fungal transgenic strains without using antibiotic resistance genes.
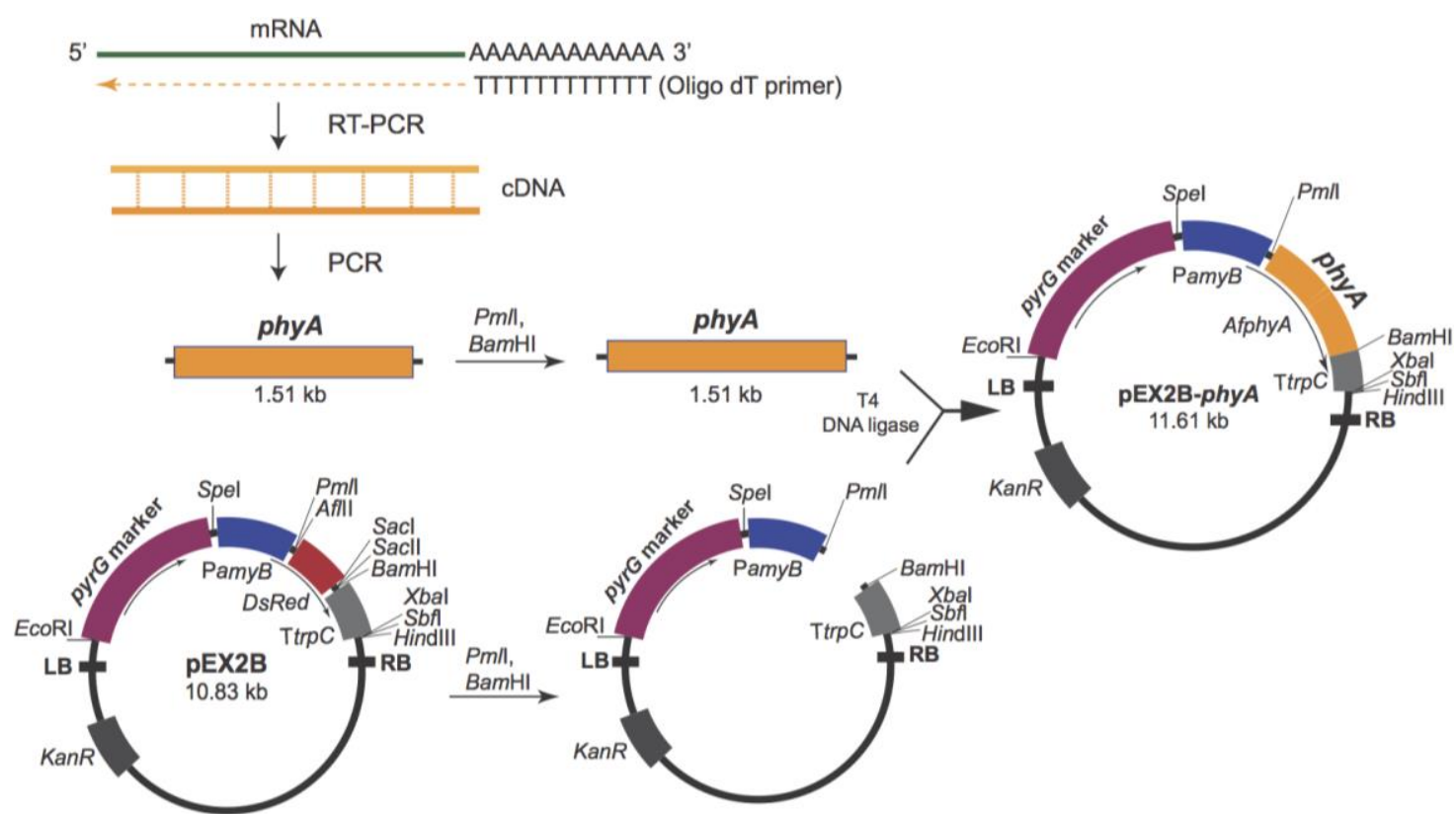

Figure 2. The diagram for the generation of the phyA expression construct. The phyA coding sequence was amplified from an A. fumigatus cDNA sample by PCR. The PCR products were treated with PmlI and BamHI prior to being ligated into the respective restriction sites in the $\mathrm{pEX} 2 \mathrm{~B}$ binary vector to generate the recombinant vector $\mathrm{pEX} 2 \mathrm{~B}-p h y A$

Genetic transformation of A. oryzae AUT1-PID using the ATMT method and the binary vector pEX2B-phyA resulted in 5-7 transformants per plate (Figure 3A). The obtained phyA expressing strains were cultivated on PSM agar plates for screening phytase activity. Bigger clearance zones of phytate degradation indicated stronger phytase activity in the transgenic strains. The nontransgenic A. oryzae AUT1-PID strain was used as the control. Three transgenic strains with the best activity for phytate degradation, designated as P1, P2, P3, (Figure 3B) were selected for DNA extraction to examine the presence of the phyA gene in fungal genomes by PCR using the specific primer pair PhyAF/PhyA-R. The results indicated that the phyA expression cassette was successfully integrated into the genomes of the selected transformants (Figure 3C). 

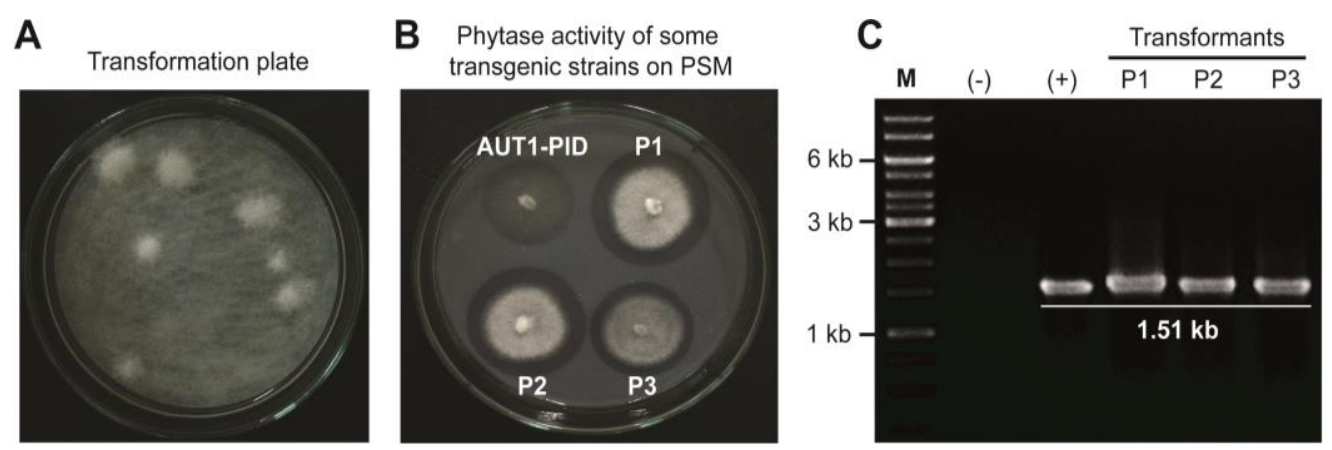

Figure 3. Transfer of the expressing construct for the A. fumigatus phyA gene into A. oryzae AUT1-PID using ATMT. (A) Fungal transformants appeared on cellulose filter paper. (B) The ability for phytate degradation of three transgenic strains. (C) Confirmation of the phyA gene in the A. oryzae transgenic strains by PCR. M: $1 \mathrm{~kb}$ DNA ladder, (-) and (+) correspond to the negative and positive controls, respectively

The selected transgenic strains harbored more than one copy of the $A$. fumigatus phy $A$ gene in their genomes

T-DNA of pEX2B-phyA carried both pyrG and phyA, which were simultaneously transferred into the $A$. oryzae AUT1-PID strain. Therefore, the copy number of $p y r G$ also reflected the copy number of phyA in genomes of the transgenic strains. Based on the genome database of $A$. oryzae RIB40 (http://www.aspergillusgenome.org), the $p y r G$ gene has only one copy (accession number: AO090011000868) in chromosome 7. Therefore, the RIB40 strain (the original of the AUT1-PID strain) was selected as the reference control for determining the phyA copy number in the transgenic strains $(\mathrm{P} 1, \mathrm{P} 2$, P3). The primer pair pyrG-RT-F/pyrG-RT-R was designed for specific amplification of a piece of the pyrG gene with a product size of 196 bp. Analysis of real-time PCR quantifications based on $\mathrm{Ct}$ (cycle threshold) values and the $2^{-\Delta \mathrm{Ct}}$ formula revealed the copy numbers of the A. fumigatus phyA gene in the genomes of three transgenic strains to be between 2 and 3 (Table 3 ).

The level of gene expression strongly relied on the copy number of the gene in the host cell (Li et al., 2013). Our results showed that three selected strains harbored 2 or 3 copies of the phyA expression cassette in their genomes (Table 3). The transgenic strain $\mathrm{P} 2$ with a high phytase activity on PSM (Figure 3B) exhibited the integration of 3 copies of the phyA gene in its genome (Table 3).

Table 3. The copy numbers of the phyA gene in the transgenic strains

\begin{tabular}{|l|c|c|}
\hline \multicolumn{1}{|c|}{ Strain } & $\mathrm{Ct}$ & Copy number $\left(2^{-\Delta \mathrm{Ct}}\right)$ \\
\hline AUT1-PID & - & 0 \\
\hline RIB40 & 17.68 & 1 \\
\hline P1 & 16.47 & 2 \\
\hline P2 & 16.07 & 3 \\
\hline P3 & 16.75 & 2 \\
\hline
\end{tabular}

The strain $\mathbf{P 2}$ appears to be a promising candidate for recombinant phytase production

The strain P2 and the control strain AUT1PID were grown in the cultivation medium with added rice husk and supplemented with $2 \%$ maltose as the sole carbon source for induction of the $a m y B$ promoter. The crude enzyme solutions extracted from fungal cultures were used for phytase activity 
evaluation. The obtained results indicated that the transgenic strain P2 displayed a phytase activity level 4.3 times higher than the control strain AUT1-PID (Figure 4A). The data also showed that the amount of time suitable for optimal phytase activity of the strain $\mathrm{P} 2$ was approximately 6 to 7 days at $30^{\circ} \mathrm{C}$ (Figure 4B). In this study, we have succeeded in expressing the phyA gene from the pathogenic fungus $A$. fumigatus in the hyperproducing strain $A$. oryzae AUT1-PID. The transgenic strains can be exploited for future studies, in which the recombinant phytase will be purified and analyzed in more detail for favored characteristics such as heat stability or $\mathrm{pH}$ tolerance.
A

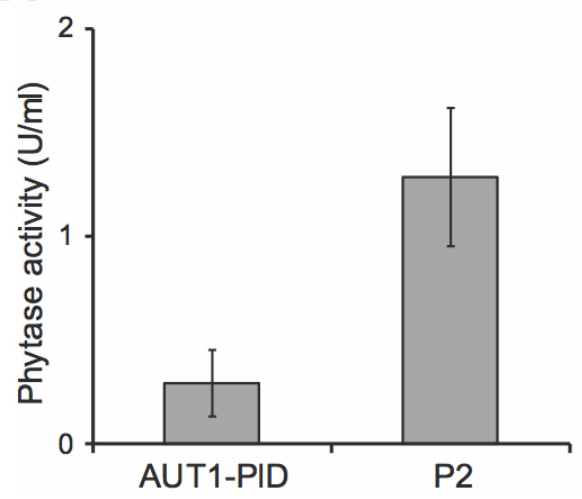

B

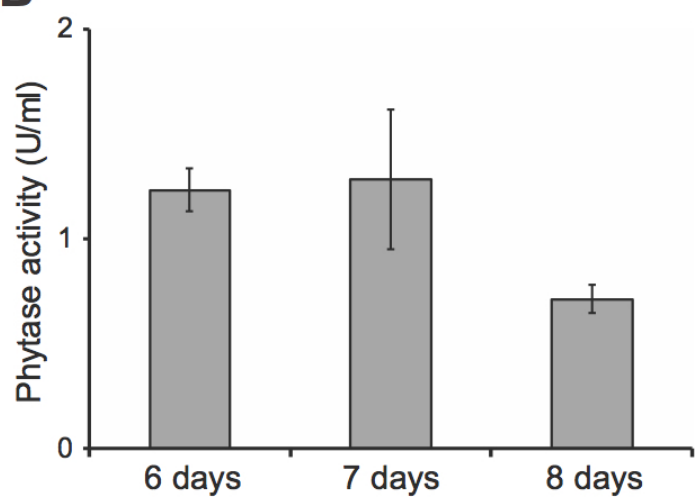

Figure 4. Phytase activity measurement. (A) Phytase activity of the phyA expressing strain P2 compared with the AUT1-PID strain when cultivated in the added rice husk medium for 7 days at $30^{\circ} \mathrm{C}$. (B) Phytase activity of the strain P2 at different time intervals of cultivation

\section{CONCLUSION}

This work demonstrated the possibility of heterologous expression of genes of interest from a fungal pathogen in the safe fungus $A$. oryzae using the cultivation model with rice husk as the carrier for ventilation. The obtained transgenic strains possessed a high efficiency for phytase biosynthesis in this cultivation model. Heterologous expression of phytases in A. oryzae using the cultivation model with added rice husks may be exploited for low-cost production of these secreted enzymes as animal supplements.

Acknowledgments: The authors thank MSc. Nguyen Van Minh for his support in some realtime PCR experiments. The research is funded by Vietnam National Foundation for Science and Technology Development (NAFOSTED) under grant number: 106.04-2018.36.

\section{REFERENCE}

Barbesgaard P., Heldt-Hansen H. P., Diderichsen B., 1992. On the safety of
Aspergillus oryzae: a review. Appl. Microbiol. Biotechnol., 36: 569-572.

Christensen T., Woeldike H., Boel E., Mortensen S.B., Hjortshoej K., Thim L., Hansen M.T., 1988. High level expression of recombinant genes in Aspergillus oryzae. Nat. Biotechnol., 6: 1419-1422.

Haefner S., Knietsch A., Scholten E., Braun J., Lohscheidt M., Zelder O., 2005. Biotechnological production and application of phytases. Appl. Microbiol. Biotechnol., 68: 588-597.

Heinonnen J. K., Lahti R. J., 1981. A new and convenient colorimetric determination of inorganic orthophosphate and its application to the assay of inorganic pyrophosphatase. Anal. Biochem., 113: 313-317.

Huge-Jensen B., Andreasen F., Christensen T., Christensen M., Thim L., Boel E., 1989. Rhizornucor miehei triglyceride lipase is processed and secreted from 
transformed Aspergillus oryzae. Lipids, 24: 781-785.

Li M., Zhou L., Liu M., Huang Y., Sun X., Lu F., 2013. Construction of an engineering strain producing high yields of $\alpha$-transglucosidase via Agrobacterium tumefaciens-mediated transformation of Aspergillus niger. Biosci. Biotechnol. Biochem., 77: 1860-1866.

Machida M., Yamada O., Gomi K., 2008. Genomics of Aspergillus oryzae: learning from the history of koji mold and exploration of its future. DNA Res., 15: 173-183.

Michielse C. B., Hooykaas P. J. J., van den Hondel C. A. M. J. J., Ram A. F. J., 2005. Agrobacterium-mediated transformation as a tool for functional genomics in fungi. Curr. Genet., 48:1-17.

Nguyen T. K., Ho N. Q., Pham H. T., Phan T. N., Tran V. T., 2016. The construction and use of versatile binary vectors carrying pyr $G$ auxotrophic marker and fluorescent reporter genes for Agrobacteriummediated transformation of Aspergillus oryzae. World J. Microbiol. Biotechnol., 32: 204.

Nguyen T. K., Ho Q. N., Do L. T. B. X., Mai L. T. D., Pham D. N., Tran H. T. T., Le D. H., Nguyen H. Q., Tran V. T., 2017. A new and efficient approach for construction of uridine/uracil auxotrophic mutants in the filamentous fungus Aspergillus oryzae using Agrobacterium tumefaciens-mediated transformation. World J. Microbiol. Biotechnol., 33: 107.

Pasamontes L., Haiker M., Wyss M., Tessier M., van Loon A. P. G. M., 1997. Gene cloning, purification, and characterization of a heat-stable phytase from the fungus
Aspergillus fumigatus. Appl. Environ. Microbiol., 63: 1696-1700.

Punt P. J., van Biezen N., Conesa A., Albers A., Mangnus J., van der Hondel C., 2002. Filamentous fungi as cell factories for heterologous protein production. Trends Biotechnol., 20: 200-206.

Rao D. E. C. S., Rao K. V., Reddy T. P., Reddy V. D., 2009. Molecular characterization, physicochemical properties, known and potential applications of phytases: an overview. Crit. Rev. Biotechnol., 29: 182-198.

Schmittgen T. D., Livak K. J., 2008. Analyzing real-time PCR data by the comparative $C_{t}$ method. Nat. Protoc., 3: 1101-108.

Tsuchiya K., Tada S., Gomi K., Kitamoto K., Kumagai C., Tamura G., 1992. Deletion analysis of the Taka-amylase A gene promoter using a homologous transformation system in Aspergillus oryzae. Biosci. Biotechnol. Biochem., 56: 1849-1853.

Varga J., Frisvad J. C., Samson R., 2011. Two new aflatoxin producing species, and an overview of Aspergillus section Flavi. Stud. Mycol., 69: 57-80.

White T. J., Bruns T., Lee S. J. W. T., Taylor J., 1990. Amplification and direct sequencing of fungal ribosomal RNA genes for phylogenetics. PCR protocols: a guide to methods and applications, 18: 315-322.

Zhu L., Maruyama J. I., Kitamoto K., 2013. Further enhanced production of heterologous proteins by double-gene disruption ( $\triangle$ AosedD $\triangle$ Aovps 10$)$ in a hyper-producing mutant of Aspergillus oryzae. Appl. Biochem. Biotechnol., 97: 6347-6357. 